\title{
História da Sexualidade 3 - o cuidado de si
}

\author{
Marçal Henrique Rossetto Cavallari*
}

FOUCAULT, Michel. História da Sexualidade 3 - o cuidado de si. Rio de Janeiro: Graal, 2002.

O volume 3, intitulado História da Sexualidade: o cuidado de si, pode ser encaixado dentro do terceiro eixo proposto por Foucault, cuja ênfase está na relação do ser consigo. O tema da sexualidade fora escolhido, pelo filósofo, para explicar a construção do sujeito, a partir de práticas concretas da vida cotidiana. A sexualidade, nessa obra, serviu de cenário para descrever a maneira como os sujeitos constroem sua identidade e direcionam sua conduta. Além disso, ao selecionar essa temática, ele pretendeu demonstrar que a sexualidade é considerada como um dispositivo de subjetivação, pois permite desvendar alguns aspectos: como o homem se constitui como sujeito de conhecimento, de ação sobre os outros e como sujeito de ação moral sobre ele mesmo. Considerando a sexualidade como substrato de sua pesquisa, para esses volumes, Foucault buscou discorrer sobre os modos de subjetivação e de objetivação, cuja atuação interdependente resulta na transformação do ser humano em sujeito. Mas, essa atuação simultânea, estabelecida entre os processos de subjetivação e de objetivação, está vinculada à maneira pela qual ocorre a relação do sujeito consigo. O modo de o sujeito relacionar com ele mesmo esboça-se por meio de um conjunto de técnicas, que o possibilitam a se constituir como sujeito da própria existência.

Esse conjunto de técnicas, formuladas como resultado de uma disposição de saberes, criado para instituir o sujeito como objeto de conhecimento, está agrupado em: tecnologias de produção, tecnologias de signos, tecnologias de poder e em tecnologias do eu. O uso dessas técnicas possibilita, ao sujeito, relacionar-se consigo, com os outros e com o meio material e institucional no qual está inserido. $\mathrm{O}$ primeiro grupo de tecnologias possibilita que ações, pensamentos e objetos sejam produzidos ou transformados. O segundo permite formar um sistema de signos, a fim de atribuir sentidos, símbolos ou significados à vida material e ao relacionamento interpessoal e intrapessoal. As tecnologias de poder visam a determinar a conduta dos indivíduos, procurando submetê-los a determinados procedimentos e interdições, cuja finalidade reside na objetivação do sujeito. E, as tecnologias do eu, possibilitam que os indivíduos, por si mesmos ou auxiliados por outros, empreguem algumas técnicas sobre seu corpo, pensamento e conduta. Ao operar essas técnicas, o indivíduo anseia a transformação de si, a fim de atingir determinado resultado que, naquele momento, o satisfaça.

No volume 3 da História da Sexualidade destacam-se as tecnologias do eu, representante maior do eixo que constitui a relação do sujeito consigo mesmo. $\mathrm{O}$ direcionamento da conduta e as práticas aplicadas pelo indivíduo, levando-se em conta esse conjunto de técnicas que balizam seu comportamento e moral, não menosprezam as outras técnicas empregadas no processo de objetivação/subjetivação. A constituição do sujeito está associada às condições de produção da vida material, dos signos socialmente edificados e das relações de poder estabelecida entre os indivíduos. A partir dessa intersecção das tecnologias, a sexualidade é exposta como uma das trajetórias percorridas, pelo indivíduo, em seu processo de subjetivação. Durante a pesquisa sobre a sexualidade, Michel Foucault não se preocupou em descrever e detalhar o ato sexual, mas a forma com que tais práticas são utilizadas para constituir o indivíduo como sujeito de desejo. Nesse caso, ao explorar a sexualidade como cenário, o filósofo atentou a investigar a natureza da relação do sujeito consigo mesmo, a partir das práticas sexuais. O propósito desse estudo era de verificar como a subjetivação é despontada, por intermédio do sexo e dos sistemas de prescrições e de interdições advindos de sua prática. A abordagem do sexo e da sexualidade, problematizados sob a perspectiva das tecnologias do eu, é iniciada a partir de dois princípios: "conhece-te a ti mesmo" e "cuida de ti mesmo". Especificamente, as técnicas do cuidado de si, imbuídas na temática da sexualidade, mais do que um aglomerado de recomendações viáveis à construção do sujeito e sua transformação em si mesmo, são apresentadas como ideal ético (fazer da vida uma obra de arte).

A ética, na perspectiva de Foucault, corresponde ao modo como o indivíduo se constitui como sujeito moral, demonstrando a maneira com a

\footnotetext{
* Endereço eletrônico; mh.cavallari@uol.com.br
} 
qual ele tece relações com o conjunto de regras e sente-se, voluntariamente, obrigado a aplicá-lo. Por sua vez, a moral é entendida como conjunto de regras, configurando-se no sistema de prescrições e de códigos de conduta que são apresentados e sugeridos ao indivíduo. De acordo com Michel Foucault, a ética é parte da moral. Mas, enquanto esta é oferecida externamente aos sujeitos, por meio de diversos meios, aquela é referente ao modo com o qual o sujeito constitui a si mesmo como sujeito moral. Na História da Sexualidade, a moral descrita por Foucault refere-se àquela do pensamento grecoromano, cujo ideal ético é de fazer da vida uma obra de arte. Nesse caso, um estilo de vida, ou uma estética da existência, intimamente ligado à ética e moral greco-romana, deveria ser colocado em prática. A estética da existência, compreendida como produção inventiva de si, pode ser compreendida tanto como práticas de sujeição quanto percebidas como diferentes maneiras encontradas pelo sujeito de se constituir e de se conduzir moralmente.

As práticas de si não ocorrem desprendidas do meio social, mas estão associadas às técnicas que são engendradas e veiculadas externamente ao sujeito. Isso significa que o ideal ético, derivado desses procedimentos, encontra-se associado aos saberes e às relações de poder. Veiga-Neto, ao analisar o conceito foucaultiano de poder, o entende como agente ou força que é exercida sobre o estado ou a ação de um corpo. E, de acordo com ele, o filósofo francês entende o poder como sendo uma ação sobre ações. Especificamente, na História da Sexualidade, volume 3 , ao discorrer sobre as prescrições e orientações em torno do sexo e de suas implicações sociais e políticas, Michel Foucault procurou descrever o funcionamento do poder, focalizando a temática da sexualidade: "Mas, mesmo estudando minuciosamente o funcionamento do poder, a rigor esse não é o objeto de Foucault, o poder entra em pauta como um operador capaz de explicar como nos subjetivamos imersos em suas redes". (VEIGA-NETO, 2005, p.62).

Em outras palavras, as técnicas inventivas de si, resultantes da relação do ser-consigo, estão intercaladas ao ser-saber e ao ser-poder. O sujeito é produto da dinâmica e da intersecção desses três elementos, sendo constituído a partir de simultâneos processos de sujeição e de subjetivação. Segundo Foucault, o modo com que cada um entende a si e o mundo está relacionado a jogos de verdade. Esses jogos estabelecem os conceitos de falso e verdadeiro, correto, incorreto, adequado e inadequado, sinalizando o que pode ser considerado como ética. E, para perceber como os sujeitos se constituem, é preciso estudar as práticas inventivas de si e de relação consigo mesmo, presentes nos sucessivos episódios da vida cotidiana, a fim de desvendar os jogos e o conjunto de verdades que as elaboraram ou foram construídos a partir delas.

O cuidado de si, mencionado no volume 3 da História da Sexualidade, perpassa pela atividade de escrever. Ao redigir sobre os acontecimentos cotidianos, o indivíduo avalia suas ações, pois explicita tanto suas falhas, como suas virtudes. Esse exercício de meditação, conhecido como exame de consciência, reativa e recupera as regras conhecidas, consideradas como verdades a ser seguidas, e transforma a ação do indivíduo sobre o mundo e a relação consigo mesmo. Igualmente, a relação com o outro se faz por meio da escrita, pois é através dela que experiências pessoais são eternizadas no papel e, posteriormente, difundidas. Essa modalidade de funções é encontrada na correspondência, nas quais, procura-se aconselhar, animar, transmitir sobre hábitos saudáveis de alimentação, hora, frequência e modalidades de exercícios físicos, os cuidados que devem ser adotados durante os atos sexuais, enfim, de assuntos relevantes entre os correspondentes. O conteúdo dessas cartas, além de sugerir procedimentos de conduta, condizentes com as prescrições morais ao leitor, expõe aquele que as escreve, tornando sua conduta passível de avaliação. Evidentemente, essas correspondências circulam por um grupo restrito, o cidadão (homem, livre, maior de 21 anos), servindolhes para orientar a prática de sua vida pública e privada, a fim de garantir sua prosperidade e a da cidade-estado. Leitura e escrita funcionam como técnicas de si, uma vez que, tanto o redator quanto o leitor entram em contato com as prescrições vigentes, que se tornam verdades, as quais balizam as ações e pensamentos de ambos. Isso implica que os sujeitos objetivam sua conduta diária e suas percepções de mundo por meio dos exercícios de escrita e leitura. Mas, ao posicionar-se diante dos regimes de verdades, constantes nessas práticas, seja acatando-os, seja tangenciando-os, o indivíduo utiliza escrita e leitura como processos de subjetivação.

Os temas abarcados no terceiro volume da História da Sexualidade, ao serem desenvolvidos como manual de prescrições de conduta envolvem técnicas de cuidar de si, as quais são disponibilizadas aos cidadãos da pólis. O primeiro assunto, referente à interpretação dos sonhos a partir 
das práticas sexuais neles desenroladas, associa às imagens do que foi sonhado aos signos que aquela cena representa para o mundo real, cujos significados podem ter consequências boas ou ruins para o sonhador. A análise dos sonhos enquadra-se nas tecnologias dos signos. Em seguida, há a descrição de como cuidar do corpo e da alma, evidenciando-se a escolha adequada de dieta ingerida, os exercícios físicos, a abstinência (dos prazeres) e a temperança como fatores indispensáveis para obtenção de corpo e alma saudáveis. Nesse tema, denominado de cultura de si, as tecnologias da produção, transformação ou da manipulação estão em evidência. Posteriormente, os assuntos relativos ao corpo, à mulher e aos rapazes, estão atravessados, igualmente, pelas técnicas de produção, manipulação ou transformação. Ao desenvolver sobre a importância da mulher, os textos antigos remetem àquelas filhas de cidadãos, que entre as funções era de gerar descendentes saudáveis, que serão futuros guerreiros e administradores da cidade-estado. Nesse mesmo sentido, sugere-se evitar as relações sexuais com rapazes e com mulheres, prostitutas, concubinas ou escravas, a fim de evitar doenças venéreas e filhos bastardos. No entanto, o homem casado, ao assumirse como chefe de família teria de saber governá-la, pois o sucesso ou o fracasso de sua administração influenciaria sua reputação na pólis e o classificaria como apto ou não à administração pública. Apesar de indicar uma técnica, aparentemente mais visível, deve-se considerar que os temas citados anteriormente convergem às tecnologias de poder $\mathrm{e}$ às técnicas de si. A conduta adequada, indicativa de qualidade do cuidado e governo sobre si implica na capacidade de cuidar e de governar o outro (esposa, filhos, casa e a pólis).

$\mathrm{Na}$ antiguidade greco-romana, a escrita e a leitura de si são recíprocas ao cuidado do outro, uma vez que estes exercícios permitem que tanto o autor, quanto o leitor estabeleçam relações consigo mesmos pra avaliar sua conduta e direcionar a prática da vida cotidiana. $\mathrm{O}$ autoexame viabilizado pela escrita e leitura, funciona como meio de "adestramento" de si, servindo, inclusive de exemplo para o outro. Ler e escrever são técnicas que disponibilizam estilos de vida, que influenciam as técnicas referentes ao cuidado de si. Ao entrar em contato com essa estilística da existência, os indivíduos posicionam-se como seus objetos, ou seja, são por elas sujeitados. No entanto, essa sujeição decorre dentro de uma relação de liberdade, uma vez que essas técnicas de si apresentam-se como prescrições e não como práticas de controle sobre o indivíduo. Dessa forma, a escrita de si, ao oferecer técnicas para o cuidado de si, auxilia na constituição do sujeito e de sua relação com ele mesmo. Essa relação, estendida para os outros, ao contrário de visar a sujeição, propões sua subjetivação.

\section{Referências}

FOUCAULT, Michel. História da Sexualidade 3o cuidado de si. Rio de Janeiro: Graal, 2002.

FOUCAULT, Michel. A escrita de si. In: Ditos e escritos, n.o. 5. MOTTA, M.B. (org). Rio de Janeiro: Forense, 2004.

FOUCAULT, Michel. O uso dos prazeres e as técnicas de si. A ética do cuidado de si como prática de liberdade. Uma estética da existência. In: Ditos e escritos, n.o. 5. MOTTA, M.B. (org). Rio de Janeiro: Forense, 2004.

VEIGA-NETO, Alfredo. Foucault e a educação. Belo Horizonte: Autêntica, 2005.

\section{Sobre o autor:}

Marçal Henrique Rossetto Cavallari: graduado em História, pela Universidade Estadual Paulista (2001), em Pedagogia, Centro Universitário Adventista de São Paulo (2010) e Especialista em Ensino de História, REDEFOR/ UNICAMP (2013). É professor de História da rede estadual paulista e do município de Cosmópolis. Atualmente é aluno de mestrado do Programa de Pós Graduação Stricto Sensu em Educação da Universidade São Francisco, campus Itatiba. E-mail: mh.cavallari@uol.com.br

Resenha recebida em 26/08/2014

Resenha aprovada em 21/11/2014 
